\title{
The Impact of Trade in Service Restrictions on Real GDP Level: An Empirical Analysis from China and Its OBOR African Partners
}

\author{
Pei Zhi Wang. ${ }^{1, *}$, Abdul Hadi Tahir. ${ }^{2}$ \\ ${ }^{1}$ Dean of Faculty of International Trade and Economics, Shandong University of Finance and Economics, Prof. Dr. \\ in International Economics \\ ${ }^{2}$ Ph.D Candidate at Shandong University of Finance and Economics, Faculty of International, Trade and Economics \\ *Corresponding author. Email: wpzmail@126.com
}

\begin{abstract}
This paper presents an assessment of the restrictions imposed on international trade in service and its implications on real GDP levels. Countries involved in this study are China and its African partners in the one belt one road initiative namely: Algeria, Egypt, Kenya, Morocco and Tunisia. Such assessment requires a pre evaluation of the relationship between trade in service share to real GDP and real GDP levels among the economies involved in this study. The hypothesis of this paper suggests that there is a positive relationship between trade in service share to real GDP and real GDP levels and thus, restrictions associated with trade in service are of significance to real GDP levels. We have applied a simple regression analysis test on the model and found that the relationship between trade in service share to real GDP and real GDP level is negative at $2.6 \%$. Moreover, we have applied an ordinary least square regression test to examine the impact of restrictions on real GDP levels and found that only two service sectors out of five service sectors included in this study have a negative impact on real GDP levels. It is hoped that this paper encourages researchers to investigate more on this topic.
\end{abstract}

Keywords: International Trade in Service, Trade Restrictions, OLS Regression Model

\section{INTRODUCTION}

Unlike trade in goods, trade in services refers to the exchange of none manufacturing services products and a more comprehensive definition of international trade in services is provided by the four modes of supply of the WTO's General Agreement on Trade in Services, each mode of supply is then defined in sequent details (WTO GATS, 2018) [1]. Moreover, the technology advancement and international trade in service policies are viewed as considerable influential factors in enabling international trade in service to occur or otherwise [2].

Services represent the more dynamic segment of international trade. As well as being important in its own right, the services sector provides key inputs into the production and trade of all products, playing an important role in global value chains and economic development. The share of developing economies in world export of services has been growing dramatically over the past 20 years (WTO, 2018). Statistically, trade in services has shown an average of $12.16 \%$ of the world GDP within the last decade (World Bank 2018) [3]. The global growing realization of the importance of trade in services is notable; for instance; developed economies such as the United States and EU are accounting for over $60 \%$ of the world service exports, and developing economies such as China, India and Brazil are annually growing by over $15 \%$ in service exports. Moreover, as these economies strive to sustain such growth rates in service exports; other countries are also trying to adopt similar trade approaches aiming at achieving similar growth rates in service exports [4].

This paper describes the relationships and trends among economic indicators such as GDP and economic growth rates on one hand, and international trade in service (TiS) on the other, and attempts to provide possible rationales for such trends and relationships. In other words; this paper aims at investigating the sensitivity of trade in service towards other economic indicators such as real GDP levels and economic growth. Despite data inadequacy on trade in service policies, we nonetheless try to examine the implications that trade restrictions might 
impose on trade in service as well as other different, yet related economic variables. We use the Service Trade Restriction Index developed by the world-bank and referred to as (STRI) to describe the variation of individual policy measure across service sectors and countries as input variables and integrate these scores with our new econometric model that includes restrictions in measuring trade in services, which we expect to have an impact on the classical approach of measuring GDP and GDP growth rate.

\section{METHODOLOGY}

\subsection{Description of TiS Share to Real GDP and Relationship to Real GDP Level}

Before we start examining the possible impact of TiS restriction scores on real GDP of economies included in our examination, we need to disclose the relationship between TiS and real GDP. This is because if no significant relationship does exist between TiS share to real GDP and real GDP levels then logically the continuation of this experiment is expected to be fruitless. We know from the classic economic model of measuring an open economy' $s$ GDP level that net export (International Trade) is positively related to GDP level however; we will examine the nature of relationship between (TiS) within the six countries involved in this study and their respective levels of real GDP. Our empirical approach is consisted in estimating the following regression equation on our panel data of China and five partnering countries in OBOR initiative over the period from 2007 to 2016 using the data analysis and statistical model STATA.

$$
\mathrm{Y}=\beta_{0}+\beta_{1} \mathrm{X}_{1}+\varepsilon
$$

Where the explained variable $\mathrm{Y}$ is the real GDP level in USD, $\beta$ is the coefficient value of variable $X$, and the explanatory variable $\mathrm{X}$ is the TiS share to real GDP in USD, and $\varepsilon$ is an idiosyncratic error term.

\subsection{Service Trade Restriction Database (STRD)}

The Trade and International Integration unit (DECTI) of the development economics research group of the World Bank had managed a project named: Service Trade Restriction Database (STRD). This agency provides comprehensive and comparable quantitative and qualitative information that are related to international service trade policies, measures, and restrictions. The dataset of this study has been generated mainly from the world development indicators data platform (databank), and the Service Trade Restriction Database (STRD) of the World Bank, and they are available at the public website of world bank.

In this section, we describe the scope of the database in our study and the relationship among generated quantitative data such as STRI scores, real GDP, GDP annual growth rate, and TiS share to real GDP of countries involved in this study namely: Algeria, China, Egypt, Kenya, Morocco, and Tunisia. Such economic variables are then incorporated in our model to investigate the relationship between TiS share to real GDP and real GDP, followed by investigating the relationship between TiS share to real GDP with TiS restriction scores before we conclude with explaining whether or not TiS restrictions had potential implications on GDP. We assume that the data description is essential for the model result section and will help us observe and better understand the relationships and trends among these variables. Supplementary data will also be attached to the appendix of this paper.

\subsection{STRD Scores Relevance to the Model}

The operandi of generating the restrictions scores per sub-sector and then taken the weighted average scores across modes of supply to come up with an overall score per sector for each country is well elaborated in the data base of world bank.The inclusion of restriction overall scores pertaining to each country' $\mathrm{s} 5$ main service sectors will take place by running an ordinary least squares (OLS) regression analysis test for estimating the unknown parameters in our linear regression analysis model. TiS share to real GDP is treated as the dependent variable, the overall restriction scores for financial sector, telecommunication sector, retailing sector, transportation sector, and professional services sector are respectively treated as independent variables within our econometrics model. These economic variables are generated from the databank of the World Bank pertaining China and the five partnering countries in OBOR initiative over the period from 2007 to 2016 .

$$
Y=\beta_{0}+\beta_{1} X_{1}+\beta_{2} X_{2}+\varepsilon
$$

Where the explained variable $\mathrm{Y}$ is the real GDP level in USD, $\beta$ is the coefficient value of variable $X$, and the explanatory variables $X_{1}$ and $X_{2}$ are the TiS share to real GDP in percentage and service sectors restriction overall scores respectively and $\varepsilon$ is an idiosyncratic error term.

\section{EMPIRICAL ANALYSIS RESULT}

The explanation of the regression analysis results in table 2 requires us to recall that we have assumed real GDP levels to be our dependent variables and TiS shares to real GDP to be our explanatory variables. Data gathered pertaining China and 5 African countries partnering in OBOR initiative for the period from 2007 until 2016 which explains the number of observations to be 60 observations. The $\mathrm{p}$ value for the $\mathrm{f}$ test model result shows that explanatory power between the two variables does exist. As shown by the coefficient of determination that $30.59 \%$ of the variation in real GDP is explained by TiS share to real GDP. Moreover, the result of the $\mathrm{p}$ value for 
the $t$ test shows that we are $99 \%$ confident that TiS share to real GDP does not equal zero and that TiS share to real GDP has a significant effect on real GDP levels. The nature of the relationship between real GDP level and TiS share to real GDP is finally explained by the coefficient results; whereby, TiS share to real GDP and real GDP level are negatively related to each other. That means a one percent increase in TiS share to real GDP will lead to $2.6 \%$ decrease in real GDP and when TiS is zero the real GDP level is amounted to be 5.17 Billion USD.

The negative relationship explained below in table 1 between real GDP levels and TiS share to real GDP will allow us to further our investigation in search of whether TiS overall restriction scores have any impact on TiS share to real GDP or not using a simple ordinary-least-Square (OLS) regression model. Once such an impact does exist, then we may conclude that TiS overall restriction scores affect TiS share to real GDP and hence affect real GDP levels as well. However, we ought to recall that TiS overall restriction scores are pertaining to 5 main service sectors and thus we will examine the correlation relationships between TiS share to real GDP with trade in the five service sectors overall restriction scores.

From the correlation test results shown below in table 2 , a summary of the bivariate linear relationship between TiS share to real GDP, and the five main service sectors studied is provided. Having said that, the bivariate linear relationships among the service sectors are not of our focus in this paper and so we will only focus on the correlations between TiS share to real GDP against the five main service sectors. A negative relationship between TiS share to real GDP and the five service sectors is notable in the table below, whereby this negative relationship varies from been a strong negative relationship in finance service sector and telecommunication service sector to a weak negative relationship in retailing service sector, transportation service sector and professional services service sector. This means the higher TiS shares to GDP are, the lower the TiS overall restriction scores as well. In other words, the negative relationship between TiS share to real GDP and the relative TiS overall restriction score are rather moving in opposite directions. For instance; the estimate of the correlation covariance between TiS share to real GDP and TiS overall restriction score for finance sector is -0.5016 which indicates a strong negative relationship between the two variables. The same approach likewise is then applied on the rest of the service sectors in relation to TiS share to real GDP respectively. It is important however to note that these negative relationship between TiS share to real GDP and TiS overall restriction scores shown below do not prove any cause and effect relationship between the variables. Therefore, there is a need to run an ordinary least squares (OLS) regression test for estimating the unknown parameters in our linear regression model to find out whether TiS overall restriction scores actually affect the TiS share to real GDP and thus affect GDP levels or not. Next, is a presentation of the ordinary least square (OLS) regression analysis results considering real GDP levels as our explained variables, and TiS share to real GDP and service sector overall restriction scores as explanatory variables. This is then conducted for every service sector of the main five service sectors of our interest.

Table1. Result of simple-regression test for real GDP level and TiS share to real GDP

\begin{tabular}{|c|c|c|c|c|c|c|}
\hline Sourse & SS & df & MS & \multirow{4}{*}{\multicolumn{2}{|c|}{$\begin{array}{l}\text { Number of obs }=60 \\
F(1,58)=25.56 \\
\text { Prob }>f=0.0000 \\
\text { R-squared }=0.3059 \\
\text { Adj R-squared }=0.2939 \\
\text { Root MSE }=2.6 e+12\end{array}$}} & \\
\hline Model & $1.72 E+26$ & 1 & $1.72 E+26$ & & & \\
\hline Residual & $3.90 E+26$ & 58 & $6.72 E+24$ & & & \\
\hline Total & $5.61 E+26$ & 59 & $9.51 E+24$ & & & \\
\hline GDP & Coef. & Std.Err. & t & $P>|t|$ & [95\% Conf. & Interval] \\
\hline TiS & $-2.66 E+13$ & $5.25 E+12$ & -5.06 & 0.00 & $-3.71 E+13$ & $-1.60 E+13$ \\
\hline _cons & $5.17 E+12$ & $8.17 E+11$ & 6.33 & 0.00 & $3.53 E+12$ & $6.81 \mathrm{E}+12$ \\
\hline
\end{tabular}

As shown below in table 3, the $\mathrm{p}$ value for the $\mathrm{f}$ test model result shows that explanatory power between some of the variables does exist. The R-squared illustrates that $83.21 \%$ of the proportion of the variation in TiS share to real GDP is explained by our explanatory variables that are trade restrictions scores within the main five service sectors.

Moreover, the result of the $\mathrm{p}$ value for the $t$ test of TiS share to real GDP shows enough evidence to reject the null hypothesis. In other words, it proves that we are $99 \%$ confident that trade restriction scores of the five service sectors studied do not equal zero and that these restriction scores have a significant effect on TiS share to real GDP. However, the result of the $p$ value for the $t$ test of trade in Telecommunication and Professional services restriction scores do not show enough evidence to reject the null hypothesis and thus we can conclude that restriction scores in these two service sectors have no linear relationship with TiS share to real GDP while the 
remaining three service sectors do have a linear relationship with TiS share to real GDP. The nature of the relationship between TiS share to real GDP and Trade restrictions in the three service sectors that have a linear relationship with TIS share to real GDP is finally explained by the coefficient results; whereby, trade in finance service sector restriction and TiS share to real GDP are negatively related to each other. That means a one percent increase in trade in finance service sector restriction scores will lead to $1.12 \%$ decrease in TiS share to real GDP. Surprisingly, a one percent increase in trade in retailing service sector restriction scores and transportation service sector restriction scores will lead to respectively $0.41 \%$ and $0.19 \%$ increase in TiS share to real GDP. Finally, when all trade restrictions score are equal to zero then the TiS share to real GDP is almost $35 \%$ of the overall value of real GDP level.

Table 2. Correlations test result between real GDP levels, TiS share to real GDP and the five main service sectors

\begin{tabular}{c|c|c|c|c|c|c} 
& TiS & FinSec & TelSec & RetSec & TraSec & ProSec \\
\hline TiS & 1.0000 & & & & & \\
\hline FinSec & -0.5016 & 1.0000 & & & & \\
\hline TelSec & -0.5826 & 0.1987 & 1.0000 & & & \\
\hline RetSec & -0.0246 & 0.7342 & 0.2000 & 1.0000 & & \\
\hline TraSec & -0.1127 & 0.4705 & -0.5411 & -0.0162 & 1.0000 & \\
\hline ProSec & -0.0050 & 0.5147 & 0.0208 & 0.7268 & -0.1204 & 1.0000 \\
\hline
\end{tabular}

Table 3. Result of Panel-Data simple-regression test for TiS share to real GDP and the five service sectors of study

\begin{tabular}{c|c|c|c|c|c|c}
\hline TiS & Coef. & Std.Err. & $z$ & $P>|z|$ & [95\% Conf. & Interval] \\
\hline FinSec & -1.1177 & 0.1514 & -7.3800 & 0.0000 & -1.4144 & -0.8210 \\
\hline TelSec & -0.1117 & 0.0948 & -1.1800 & 0.2380 & -0.2975 & 0.0740 \\
\hline RetSec & 0.4099 & 0.4285 & 9.5700 & 0.0000 & 0.3259 & 0.4939 \\
\hline TraSec & 0.1910 & 0.0604 & 3.1600 & 0.0020 & 0.0726 & 0.3094 \\
\hline ProSec & 0.0254 & 0.0452 & 0.5600 & 0.5740 & -0.0632 & 0.1140 \\
\hline cons & 0.3477 & 0.0423 & 8.2200 & 0.0000 & 0.2648 & 0.4306 \\
\hline
\end{tabular}

\section{CONCLUSION}

International trade in service is a key prerequisite component for economic development and augmentation. By right, without the assistance international TiS provides; economies would not be able to perform well in the manufacturing sector rather than achieving higher levels of economic growth. That is the case due to the world's various economic regions rapid yet steady engagement with various service sectors which allows TiS to play a vital role in provision for manufacturing sector.

A key contribution of this paper was to prove that TiS share to real GDP levels of the economies involved in our study for the period from 2007 until 2016 have a relationship with real GDP levels of the same economies. This relationship however is found to be a negative relationship. Moreover, despite the negative relationship found in our correlations analysis model between TiS share to real GDP and TiS five main service sectors restriction scores; such negative relationship has been proven to have no negative impact on the TiS share to real GDP and thus on real GDP levels of the economies investigated in our study. Finance, Retailing, and
Transportation service sectors however are exceptions to this conclusion whereby, Finance service sector is found to have a significant negative relationship with TiS share to real GDP level. Surprisingly, Retailing and Transportation service sectors are found to have a significant positive relationship with TiS share to real GDP level. The fact that all the countries involved in our study are involved more in agriculture industries and manufacturing industries rather than service industries is crucial to this regard.

Economies with high output level such as OECD members are found in Borchert, Gootiiz and Mattoo (2013) to have more restrictions on Professional service sectors and Transportation service sectors [4]. Additionally, economies such as the GCCs and fast growing economies in Asia that enjoy high level of income also show higher international TiS restriction scores relatively [5]. On the other hand, countries like Mongolia, Ghana and Senegal are associated with relatively lower international TiS restriction scores yet they are still unable to achieve a high level of income relatively. Such patterns might require more investigations as well. 
Having said that, why would world-recognized entities such as the World-Bank and the World Trade Organization do invest much of their efforts and resources on lessening restrictions associated with international TiS [6]? Having other things remain equal, perhaps the gap between presumed trade policies and actual trade policies and their cause and effect on the dynamic circle of international TiS within economies studied can be a potential subject matter for future experiments.

\section{REFERENCES}

[1] S. Shekhar, Definition of Trade in Services: A Critical Analysis, 2013.

[2] A. Mattoo, R. Rathindran, A. Subramanian, Measuring services trade liberalization and its impact on economic growth: An illustration. Journal of Economic Integration, 2006, pp. 64-98.

[3] R. Mullings, A. Mahabir, Growth by Destination: The Role of Trade in Afric's Recent Growth Episode. World Development, 2018, 102, 243-261.

[4] I. Borchert, B.Gootiiz, A. Mattoo, Policy barriers to international trade in services: evidence from a new database. The World Bank Economic Review, 2013, 28(1), 162-188.

[5] R. Pradhan, M. Arvin, B. Hall, N. R. Norman, ASEAN economic growth, trade openness and banking-sector depth: The nexus. EconomiA, 2017, 18(3), 359-379.

[6] X. Bao, L. D. Qiu, Do technical barriers to trade promote or restrict trade? Evidence from China. Asia-Pacific Journal of Accounting Economics, 2010, 17(3), 253-278.

[7] M. Matsushita, T. J. Schoenbaum, P. C. Mavroidis, M. Hahn, The World Trade Organization: law, practice, and policy. Oxford University Press, 2015.

[8] I. Borchert, B. Gootiiz, A. Mattoo, Guide to the services trade restrictions database, 2012.

[9] H. Nordås, What drives trade in services? Lessons from the Nordics. Applied Economics, 2018, 1-14.

[10] M. G. Grosso, F. Gonzales, A. Ueno, Services Trade Restrictiveness Index (STRI): scoring and weighting methodology, 2015.

[11] N. Ketenci, I. Uz, Trade in services: The elasticity approach for the case of Turkey. The International Trade Journal, 2010, 24(3), 261-297.

[12] W. R. Hauk, Trade restriction indices and US trade policy. Applied Economics Letters, 2012, 19(8), 795-799.
[13] H. K. Nordås, Services trade restrictiveness index (STRI): the trade effect of regulatory differences, 2016.

[14] H. Kim, S. Lin, Y. B. Suen, Trade, growth and growth volatility: New panel evidence. International Review of Economics Finance, 2016, 45, 384-399.

[15] M. Stare, A. Jaklič, Transition, regulation and trade in services. The Service Industries Journal, 2008, 28(3), 277-290.

[16] D. Bräutigam, T. Xiaoyang, African Shenzhen: China's special economic zones in Africa. The Journal of Modern African Studies, 2011, 49(1), 27 54.

[17] J. Gourdon, S.Monjon, S. Poncet, Trade policy and industrial policy in China: What motivates public authorities to apply restrictions on exports?. China Economic Review, 2016, 40, 105120.

[18] R. Baldwin, Trade and industrialisation after globalisation's 2nd unbundling: How building and joining a supply chain are different and why it matters. National Bureau of Economic Research, 2011.

[19] E. Helpman, Imperfect competition and international trade: evidence from fourteen industrial countries. Journal of the Japanese and international economies, 1987, 1(1), 62-81.

[20] X. Liu, P. Burridge, P. J. Sinclair, Relationships between economic growth, foreign direct investment and trade: evidence from China. Applied economics, 2002, 34(11), 1433-1440.

[21] T. Altenburg, Industrial policy in developing countries: overview and lessons from seven country cases, 2011.

[22] A. Isaksen, M. Trippl, Regional industrial path development in different regional innovation systems: A conceptual analysis. Lund University, CIRCLE-Center for Innovation, Research and Competences in the Learning Economy, 2014, 17.

[23] D. Bräutigam, T. Xiaoyang, African Shenzhen: China's special economic zones in Africa. The Journal of Modern African Studies, 2011, 49(1), 27 54.

[24] K. Warwick, Industrial Policy: Emerging Issues and New Trends, 2013.

[25] J. Shen, H. Li, An Empirical Analysis on Industrial Organization Structure of Chinese Software Service Outsourcing. Journal of Service Science and Management, 2010, 3(02), 218.

[26] C. Hackenesch, Aid donor meets strategic partner? The European Union's and China's relations with Ethiopia, 2013. 